\title{
Estimation of Fuel Consumption in a Hybrid Electric Refuse Collector Vehicle using a Real Drive Cycle
}

\author{
Ernest Cortez, Manuel Moreno-Eguilaz, Francisco Soriano, Enric Sala Cardoso \\ Department of Electronic Engineering \\ MCIA - UPC - BarcelonaTech, Terrassa, Spain \\ Email: ernest.cortez@mcia.upc.edu
}

\begin{abstract}
This paper presents a new methodology to estimate the fuel economy in a hybrid electric refuse collector vehicle (RCV). This methodology is based on determinating the fuel consumption in a conventional RCV using real routes, through a quasi-static model that incorporates a mathematical modeling of each component of the powertrain, including the longitudinal dynamic of the conventional RCV. Moreover, a classification of different operational modes of a conventional RCV using real routes is proposed to determinate the required energy that must be provided by the hybrid electric counterpart. The optimal sizing of the energy storage system for the hybrid electric powertrain is presented in order to estimate the fuel consumption by using a real route. The error in the estimation of fuel consumption in a conventional $\mathrm{RCV}$ is less than $1.5 \%$ in the worst case scenario. The energy storage system sizing allows a $8.62 \%$ reduction in the hybrid electric refuse collector vehicle's fuel consumption, by considering $10 \%$ of hybridization.
\end{abstract}

\section{NOMENCLATURE}

ECM Engine control module

$F_{t} \quad$ Traction force

$m_{v}, m_{d} \quad$ Static and dynamic vehicle mass

$\rho_{a} \quad$ Air density

$\eta_{t} \quad$ Transmission efficiency

$\alpha \quad$ Road angle

$P_{r t} \quad$ Losses idling power

$v, v_{c} \quad$ Speed and coasting speed

$\tau_{v-t}$

$w_{v-t}$

$\tau_{t-I C E}$

$w_{t-I C E}$

$P_{I C E}$

$\tau_{t-E M}$

$w_{t-E M}$

$P_{E M-E S S}$

$P_{E G-E M}$

$P_{E G-E S S}$

$\tau_{I C E-E G}$

Torque from vehicle to transmission

Angular speed from vehicle to transmission

Torque from transmission to ICE

Angular speed from transmission to ICE

Power of ICE

Torque from transmission to electric motor

Angular speed transmission electric motor

$w_{I C E-E G}$

Power electric motor to energy storage system Power electric generator electric motor

Power electric generator energy storage system Torque ICE to electric generator

Bat $_{i}$, BatCost $_{i}$ Type and cost of battery

$\mathrm{BatSel}_{i} \quad$ Selection of battery type

BatVoltage $_{i} \quad$ Voltage of battery type

$E_{r} \quad$ Energy required

$P B \quad$ Lead-acid battery

$N i-M H$
LiPo
Li-ion
ICE $E_{\text {on-off }}$
auxICE
$M_{\text {dem }}$
$G_{p}$
$E_{\text {pd }}$
ESS $_{c}$
SoC
Currrent
nom

Nickel metal hydride baterry

Lithium polymer battery

Lithium-ion batery

On-off state of ICE

Auxiliary on-off state of ICE

Motor demand

Generator power

Energy power demand

Energy storage system capacity

State of charge

Nominal current of the energy storage system

\section{INTRODUCTION}

A growing concern has been generated along the world by an environmental care and an excessive petroleum consumption. The Stern review about climatic change assures that the transport represents the $14 \%$ of the global gas emissions greenhouse effect, being the third greatest source of emissions along with agriculture and industry [1], [2].

The serious environmental problems and the studies that foresee the shortage of fossil fuel in the next decades require a greater attention to the impact of industrial vehicles. Refuse collection vehicles (RCVs) represent a specific application in the automotive industry. Although they share diverse aspects with other types of vehicles, they are distinguished by specific circumstances such as the total weight variation, repetitive and aggressive drive cycles, as a result of labor activity [3], [4].

Nowadays, the RCV sector has a scarce study and a lack of research focused on the development of new methodologies in the analysis of drive cycles, sizing of the powertrain, particulary sizing of the energy storage system, and control strategies for the energy management that permits the reduction of fuel consumption [4].

The fuel consumption of an internal combustion engine (ICE) is determined through a non-linear static map denominated brake specific fuel consumption (BSFC), which describes the fuel mass flow required to produce a determined torque and the angular speed in the engine at steady state [5].

Various studies have been developed by using real drive cycles in order to estimate the fuel consumption of an ICE [6][10]. Commonly, standard drive cycles has been established 


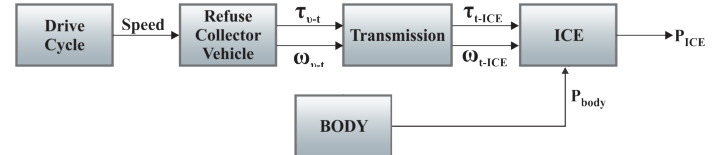

Fig. 1. Quasi-static model of an RCV.

by different countries and organizations with the purpose of evaluation of the vehicle performance.

Several studies are based on standard drive cycles [11]- [14]. The main problem of this approach lies in the differences that exist between the drive profile established through a standard and the speed profile of a vehicle on real conditions.

An approach that uses real drive cycles to estimate the fuel consumption of an ICE in an RCV by taking into account the longitudinal dynamic of the vehicle (including aerodynamic resistance, rolling resistance, resistance to the road profile, inertial resistance and the energy consumed from the vehicle body) is proposed in [15].

In this work a methodology will be developed to estimate the fuel economy in a hybrid electric refuse collector vehicle using real routes. Afterwards, there will be a classification of different operational modes in order to do an optimal sizing of the energy storage system for the hybrid electric powertrain.

In section II the quasi-static model of an RCV and the mathematical model of each component of the powertrain is presented. Section III describes the acquisition of the speed profile of an Iveco Stralis GNC 270 RCV in real conditions, and the drive cycle classification deduced from the equation that describes the longitudinal dynamic of an RCV, the required energy and the contribution of the fuel consumption are determinated. Section IV describes the optimal sizing of the energy storage system for the hybrid electric powertrain considering the weight minimization as the objective function. In section $\mathrm{V}$ the quasi-static model of a hybrid electric RCV is presented by using the sizing optimization results, and the fuel economy is estimated. Following, in section VI the result analysis is presented. Finally, section VII provides main conclusions of the paper.

\section{QuAsi-STATIC Model of a Refuse COLlection VEHICLE}

It is possible to estimate the fuel consumption of an RCV from a quasi-static model (see Fig. 1) [16], which incorporates the mathematical modeling of each component in the powertrain and includes the longitudinal dynamic of the vehicle, where is considered a dynamic weight related to refuse collector which was the main aim of the RCV.

Applying the Newton's second law in order to analyze the main forces, Fig. 2, it is possible to determine equation (1), that describes the longitudinal dynamic of an RCV [3], [15], [17].

$$
\left(m_{v}+m_{d}(t)\right) \cdot \frac{d}{d t} v(t)=F_{t}(t)-\left(F_{a}(t)+F_{r}(t)+F_{g}(t)\right)
$$

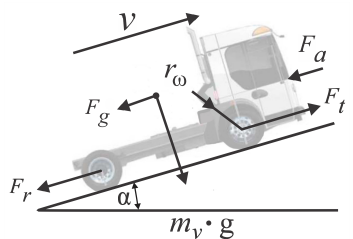

Fig. 2. Quasi-static model of an RCV.

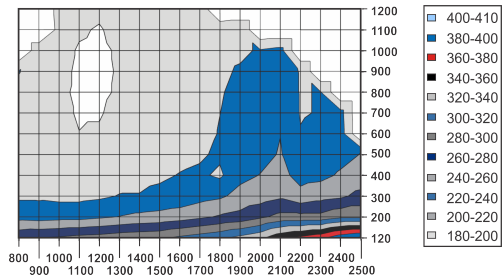

Fig. 3. BSFC map of an RCV.

where $F_{a}$ is the aerodynamic resistance (2), $F_{r}$ is the rolling resistance (3), and $F_{g}$ is the force caused by gravity during a route on a non-horizontal road (4).

$$
\begin{gathered}
F_{a}=\frac{1}{2} \cdot \rho_{a} \cdot v^{2} \cdot A_{f} \cdot C_{d} \\
F_{r}=\left(m_{v}+m_{d}(t)\right) \cdot g \cdot C_{r} \cdot \cos (\alpha) \\
F_{g}(\alpha)=\left(m_{v}+m_{d}(t)\right) \cdot g \cdot \sin (\alpha)
\end{gathered}
$$

The transmission is an important component of the powertrain, due to the transformation that is performed from torque and angular speed of the ICE to a determined torque (5) and the angular speed (6), both defined by the gear ratio $(\gamma)[18]$, [19].

$$
\begin{aligned}
\omega_{t-I C E} & =\gamma \cdot \omega_{v-t} \\
\tau_{t-I C E} & =\frac{1}{\gamma} \cdot \tau_{v-t}
\end{aligned}
$$

It is important to take into account that the power flow in the transmission, based on the operation mode of the vehicle, is defined by the positive power flow direction $\tau_{v-t}>0$, as shown in (7), and the negative one $\tau_{v-t}<0$, as shown in (8).

$$
\begin{aligned}
\tau_{t-I C E} & =\frac{1}{\gamma \cdot \eta_{t}}\left(\tau_{v-t}+\frac{P_{r t}}{\omega_{v-t}}\right) \\
\tau_{t-I C E} & =\frac{1}{\gamma}\left(\eta_{t} \cdot \tau_{v-t}+\frac{P_{r t}}{\omega_{v-t}}\right)
\end{aligned}
$$

The mass flow $(\dot{m})$ is calculated through (9), considering the RCV BSFC map as shown in Fig. 3.

$$
\dot{m}=B S F C\left(\tau_{t-I C E}, \omega_{t-I C E}\right) \cdot \tau_{t-I C E} \cdot \omega_{t-I C E}
$$

The ICE power output can be determined by (10), which is based on lower heating value of a determinate fuel and the mass flow required for the ICE in order to know the required energy for the conventional RCV using real drive cycles [16].

$$
P_{I C E}=\dot{m} \cdot L H V
$$




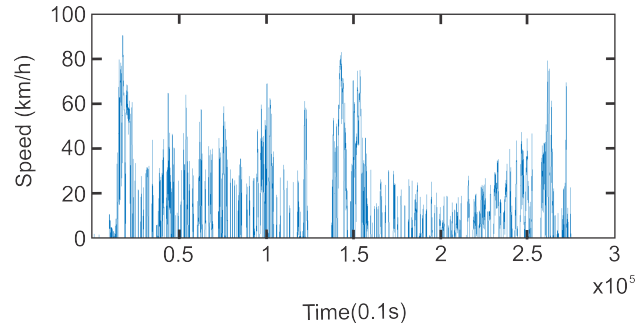

Fig. 4. Drive cycle of March 8, 2013.

\section{Classification of the Drive Cycle}

\section{A. Drive Cycle}

The quasi-static model requires a drive cycle that establishes a drive profile in order to determine the fuel consumption of an ICE in an RCV [16]. Nowadays, several countries and organizations have established standard drive cycles that pretend to describe a determined drive profile.

However, a standard drive cycle does not provide an accurate approximation of a drive cycle in real conditions. Therefore, it is proposed to use a real RCV drive cycle to estimate the fuel consumption with greater accuracy, taking in consideration specific parameters of the vehicle and the duty cycle.

To obtain a real drive cycle (as shown in Fig. 4) a datalogger CANalyzer CANCase XL with two CAN ports (SN 007130011289) is used, allowing the storage of torque and rpms of the ICE. These parameters are obtained from the ECM, through the communication bus of an Iveco Stralis GNC 270 RVC during an 8-hour workday.

\section{B. Classification}

It is intended to classify the real drive cycle according to the several operation modes of an RCV. This classification will allow to determine the fuel consumption for each of the operation modes, resulting in the improvement of the fuel consumption estimation of the ICE.

Using (1), it is possible to relate the traction force on the wheels (11) as the sum of the acceleration force of the vehicle, aerodynamic resistance, rolling resistance and the force caused by gravity.

$$
F_{t}(t)=\left(m_{v}+m_{d}(t)\right) \cdot \frac{d}{d t} v(t)+F_{a}(t)+F_{r}(t)+F_{g}(t)
$$

Depending on the traction force $F_{t}(t)$, three operation modes [20], [21] are defined:

- Traction Mode: $F_{t}>0$

- Braking Mode: $F_{t}<0$

- Coasting Mode: $F_{t}=0$

Assuming that $F_{t}=0$ during a route and considering the horizontal $\operatorname{road}(\alpha=0)$, it is possible to determine the coasting speed $v_{c}(t)$ of an industrial vehicle through the solution of the following ordinary differential equation:

$$
\frac{d}{d t} v_{c}=-\frac{1}{2 \cdot\left(m_{v}+m_{d}(t)\right)} \rho_{a} \cdot v^{2} \cdot A_{f} \cdot C_{d}-C_{r} \cdot g
$$

TABLE I: RCV parameters

\begin{tabular}{|l|r|}
\hline Combustion engine & $200 \mathrm{~kW}$ \\
\hline Gears & 6 \\
\hline Gear ratios $(\gamma)$ & $1(4.59), 2(2.25), 3(1.54)$ \\
& $4(1.000), 5(0.75), 6(0.65)$ \\
\hline Weight $\left(m_{v}\right)$ & $15,000 / 25,000 \mathrm{~kg}$ \\
$($ Empty / Full loaded) & $7.5 \mathrm{~m}^{2}$ \\
\hline Frontal area $\left(A_{f}\right)$ & 0.6210 \\
\hline Drag coefficient $\left(C_{d}\right)$ & .009 \\
\hline Rolling resistance $\left(C_{r}\right)$ & $315 / 80 / \mathrm{R} 22,5(0.5455 \mathrm{~m})$ \\
\hline Tire ( Radius $)$ & \\
\hline
\end{tabular}

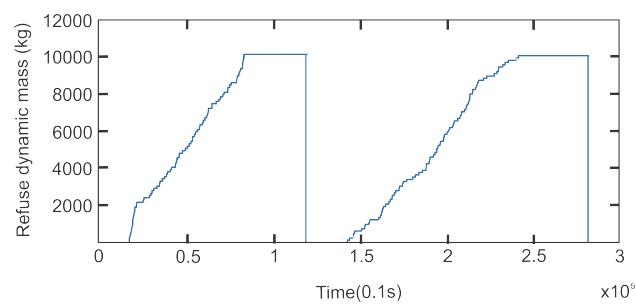

Fig. 5. Refuse dynamic mass.

The solution of this ordinary differential equation (13) defines the operation modes by using the coasting speed $v_{c}(t)$ :

$$
\begin{gathered}
v_{c}(t)=\sqrt{\frac{-c_{r} \cdot g \cdot \cos (\alpha)-g \cdot \sin (\alpha)}{\frac{\rho_{a} \cdot A_{f} \cdot C_{d}}{2 \cdot\left(m_{v}+m_{d}(t)\right)}}} . \\
\tanh \left\{\operatorname { t a n h } ^ { - 1 } \left(\sqrt{\left.\left.\frac{\frac{\rho_{a} \cdot A_{f} \cdot C_{d}}{2 \cdot\left(m_{v}+m_{d}(t)\right)}}{2 \cdot g \cdot \cos (\alpha)-g \cdot \sin (\alpha)} \cdot v(0)\right)-\beta\right\}}\right.\right. \\
\beta, \sqrt{\left(\frac{\rho_{a} \cdot A_{f} \cdot C_{d}}{2 \cdot\left(m_{v}+m_{d}(t)\right)}\right) \cdot\left(-C_{r} \cdot g \cdot \cos (\alpha)-g \cdot \sin (\alpha)\right) \cdot t}
\end{gathered}
$$

Starting with the same initial speed $v_{c}(0)$, during a limited range of time, it is possible to determine the corresponding operation mode as:

- Traction Mode, if $v_{c}(t)>v_{c}(0)$

- Braking Mode, if $v_{c}(t)<v_{c}(0)$

- Coasting Mode, if $v_{c}(t)=v_{c}(0)$

By using real routes, it is proposed to perform a preprocessing of each individual cycle to establish a state denominated IDLE, in which the vehicle is stopped. Afterwards, it is proposed to classify the drive cycle making use of (13) using specific parameters of conventional an RCV (Table I) obtained from [4], in order to determine the operation modes. The dynamic weight consists of a profile of refuse mass collector in a determinate route (as shown in Fig. 5).

The angular speed $\omega_{v-t}$ (Fig. 6) and the torque $\tau_{v-t}$ (Fig. 7) are determined, by using (1), allowing the estimation of the flow direction power in the transmission (7 or 8), the angular speed $\omega_{t-I C E}$ (as shown in Fig. 6) and the torque $\tau_{t-I C E}$ (as shown in Fig. 9).

It is possible to estimate the required fuel for the RCV by using (9). Points, time and fuel consumption for each mode using the real drive are shown in Table II. 


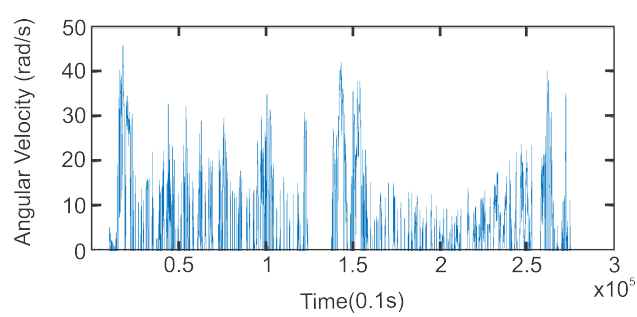

Fig. 6. Vehicle-Transmission angular speed.

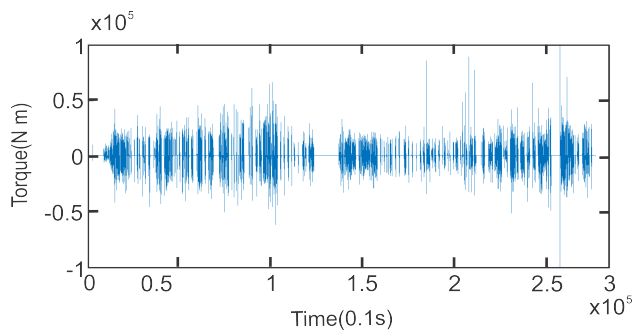

Fig. 7. Vehicle-Transmission torque.

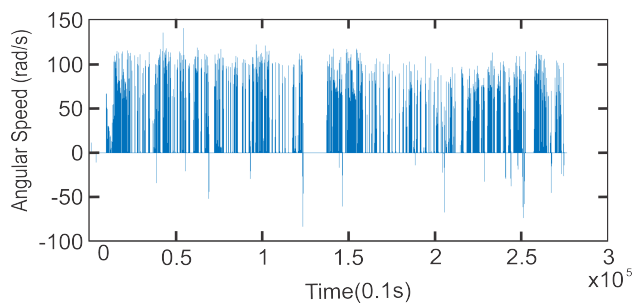

Fig. 8. Transmission-ICE angular speed.

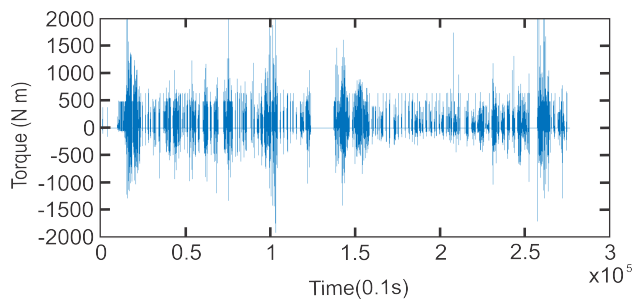

Fig. 9. Transmission-ICE torque.

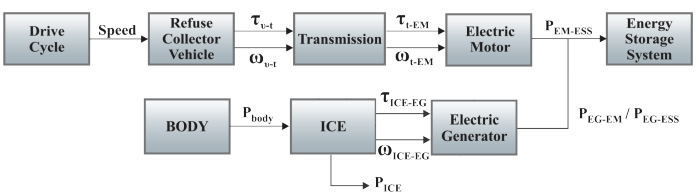

Fig. 10. Quasi-static model of a hybrid electric RCV.

\section{Quasi-STatic Model of a Hybrid Electric Refuse Collection Vehicle}

The hybrid electric RCV counterpart shares similarities on a quasi-static model that describes the mathematical model of each component in the powertrain. The topology consists of the related connection of all the components as a part of the powertrain. In order to calculate the fuel consumption, a serial topology (as shown in Fig. 10) has been proposed to be used in this paper.

It is possible to determine differences between the components of each model, such as the electric motor/generator
TABLE II: Drive cycle classification

\begin{tabular}{|c|c|c|c|c|c|}
\hline Description & Idle & Tracking & Braking & Coasting & Total \\
\hline Time (Hrs.) & 4.1 & 2.1 & 1.44 & 0.02 & 7.67 \\
\hline $\begin{array}{c}\text { Consumption } \\
\text { (kg) }\end{array}$ & 14.29 & 29.35 & 3.91 & 0.07 & 47.63 \\
\hline
\end{tabular}
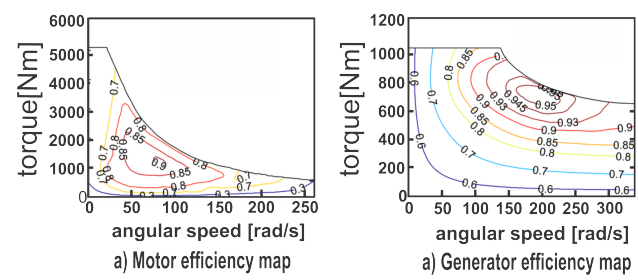

Fig. 11. Electric motor/generator efficiency map.

and the energy storage system. The electric motor/generator equation described by (14), depends on a non-linear static map of efficiency (EMGEM)(as shown in Fig. 11).

$$
\begin{aligned}
P_{E M-E S S}= & E M G E M\left(\tau_{t-E M}, \omega_{t-E M}\right) \\
& \cdot \tau_{t-E M} \cdot \omega_{t-E M} \\
P_{E G-E M} / P_{E G-E S S}= & E M G E M\left(\tau_{I C E-E G}, \omega_{I C E-E G}\right) \\
& \cdot \tau_{I C E-E G} \cdot \omega_{I C E-E G}
\end{aligned}
$$

The energy storage system (ESS) is a source that provides electric power to the powertrain in a HEV. Batteries and supercapacitors [22] are two of the most well-known types of ESS components in the HEV literature. The ESS optimization can be accomplish through sizing and powertrain components costs optimization [23].

\section{Optimal Powertrain Sizing}

Optimization problem (15) implies the objective function that minimizes the weight of energy storage system for hybrid electric refuse collector vehicle with serial topology, through selecting among four types of batteries. In addition, there are some constraints related to the cost and density energy required by the RCV based on the quasi-static model and the percentage of hybridization desired.

$$
\min Z=\sum_{i}^{n} \# \text { Bat }_{i} \cdot \text { BatCost }_{i} \cdot \text { BatSel }_{i}
$$

subject to

$$
\begin{aligned}
& \sum_{i}^{n} \# \text { Bat }_{i} \cdot \text { BatCost }_{i} \cdot \text { BatSel }_{i}<\text { Cost } \\
& \sum_{i}^{n} \# \text { Bat }_{i} \cdot \text { BatVoltage }_{i} \cdot \text { Current }^{\prime} \text { BatSel }_{i}>=E_{r} \\
& \sum_{i}^{n} \text { BatSel }_{i}=1 \\
& \# \text { Bat }_{i}, \text { BatSel } \epsilon \text { Integer }_{\text {where }, i=P B \vee N i-M H \vee \text { LiPo } \vee L i-i o n}
\end{aligned}
$$


TABLE III: Optimization result

\begin{tabular}{|l|l|}
\hline Capacity & $13.8 \mathrm{kWh}$ \\
\hline Weight & $92 \mathrm{~kg}$ \\
\hline Nominal Voltage & $331.2 \mathrm{v}$ \\
\hline Current & $41.66 \mathrm{~A}$ \\
\hline Cost & $€ 1,076.4$ \\
\hline
\end{tabular}

TABLE IV: Fuel consumption comparison

\begin{tabular}{|c|c|c|c|}
\hline & ECM & Calculated & Error \\
\hline Fuel consumption & $48.32 \mathrm{~kg}$ & $47.63 \mathrm{~kg}$ & $-1.4196 \%$ \\
\hline
\end{tabular}

Following, taking into account the constraints an optimization technique can be selected. The optimization problem has been resolved by using mixed integer linear programming, considering $10 \%$ of hybridization and a proposed maximum cost of $€ 2,000$. The resulting battery pack of the optimization process is shown in Table III.

\section{Result Analysis}

The fuel consumption estimation is obtained through a quasistatic model. The inclusion of real transmission parameters in the quasi-static model increases the accuracy of the results, due to the interconnection existing in other stages.

Using the acquired angular speed and the engine torque from the ECM, the fuel consumption has been determined in order to perform a comparison with the fuel consumption through the developed methodology (Table IV).

The classification of the drive cycle allows the determination of the time and the contribution of fuel consumption, considering the parameters of the real refuse collector vehicle and a real route.

The rule based control of charge/discharge of ESS was proposed in order to calculate the fuel consumption. Five rules were written for the controller $(16,17,18,19,20)$. It manipulates the on/off state of the ICE in function of the required energy by RCV and the state of charge of the energy storage system.

$$
\begin{gathered}
\text { if }\left(\text { auxIC } E_{\text {on-off }}==1\right) \text { then } \\
I C E_{\text {on-off }}=O F F \\
\text { aux } I C E_{\text {on-off }}=0
\end{gathered}
$$

$$
\begin{gathered}
\text { if }\left(M_{\text {dem }}>E S S_{c} \quad \text { and } \quad I C E_{\text {on-off }}==O N\right) \text { then } \\
E_{p d}=M_{\text {dem }}-G_{p} \\
\text { if }\left(G_{p}>M_{\text {dem }}\right) \text { then } \\
\text { if }\left(S o C>=S o C_{\max }\right) \text { then } \\
I C E_{\text {on-off }}=\text { OFF } \\
\text { else }\left(\text { SoC }>=S o C_{\max }\right) \text { then } \\
\text { if }\left(-E_{p d}>E S S_{c}\right) \text { then } \\
E_{p d}=-E S S_{c} \\
\text { SoC }=\text { SoC }-\frac{E_{p d} \cdot \text { Step }}{\text { Current }} \text { nom }
\end{gathered}
$$

TABLE V: Comparative results

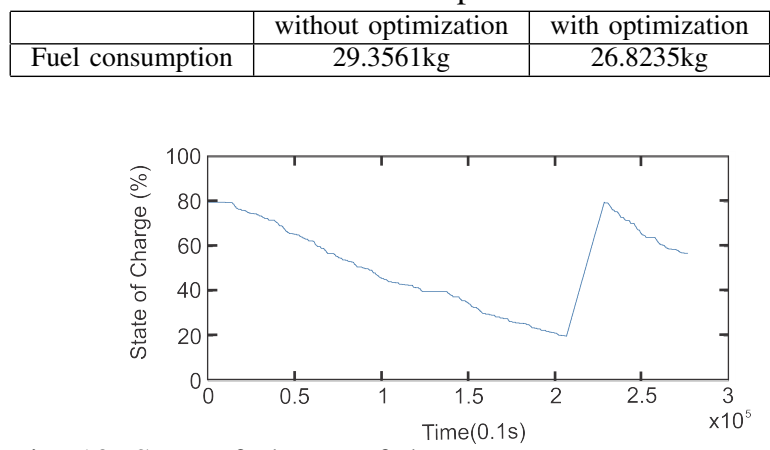

Fig. 12. State of charge of the energy storage system.

$$
\begin{aligned}
& \text { if }\left(M_{\text {dem }}<=E S S_{c} \quad \text { and } \quad I C E_{\text {on-off }}==O N\right) \text { then } \\
& E_{p d}=M_{d e m}-G_{p} \\
& \text { if }\left(S o C>=S o C_{\max }\right) \text { then } \\
& I C E_{\text {on-off }}=O F F \\
& \text { else } \\
& \text { if }\left(-E_{p d}>E S S_{c}\right) \text { then } \\
& E_{p d}=-E S S_{c} \\
& \text { SoC }=S o C-\frac{E_{p d} \cdot \text { Step }}{\text { Current }_{\text {nom }}}
\end{aligned}
$$

$$
\begin{aligned}
& \text { if }\left(M_{\text {dem }}>E S S_{c} \quad \text { and } \quad I C E_{\text {on-off }}==O F F\right) \text { then } \\
& I C E_{\text {on-off }}=O N \\
& \text { auxICE } E_{\text {on-off }}=1 \\
& \text { SoC }=\text { SoC }-\frac{\text { ESS } S_{c} \cdot \text { Step }}{\text { Current }_{n o m}}
\end{aligned}
$$

$$
\begin{gathered}
\text { if }\left(M_{\text {dem }}<=E S S_{c} \quad \text { and } \quad I C E_{\text {on-off }}==O F F\right) \text { then } \\
\text { if }\left(S o C<=S o C_{\text {min }}\right) \text { then } \\
I C E_{\text {on-off }}=O N \\
\text { SoC }=S o C-\frac{M_{\text {dem }} \cdot \text { Step }}{\text { Current }_{\text {nom }}}
\end{gathered}
$$

Afterwards, the quasi-static model can be simulated with the optimization results, the feedback weight in the model is taking into account in order to consider the effect on the fuel consumption. The $20 \%$ minimum and $80 \%$ maximum of state of charge are considered in the battery. The fuel consumption in the conventional quasi-static model is recalculated in order to eliminate the effect of consumption in IDLE, braking and coasting modes.

Table $\mathrm{V}$ presents the fuel consumption estimation of refuse collector vehicle with optimization and without the optimization.

Finally, is possible to corroborate the correct function of the charge/discharge control of energy storage system (as shown in Fig. 12). 


\section{CONCLUSION}

A new methodology has been developed to allow the estimation of fuel economy in a hybrid electric RCV, taking into account a real drive cycle.

The proposed methodology determines the mass flow in a conventional Iveco Stralis GNC 270 RCV through the use of a quasi-static model, obtaining less than $1.5 \%$ error in the estimation of fuel consumption compared to fuel consumption reported by the J1939 protocol.

Further, a real route has been used to classify different operational modes of a conventional $\mathrm{RCV}$, in order to determine the required energy. Using an optimization technique for the powertrain energy storage system sizing, results in a $8.62 \%$ fuel reduction, taking into account $10 \%$ hybridization.

The J1939 communication protocol and conventional RCV fuel consumption are calculated in a comparative analysis. Afterwards, the optimal energy storage system was discussed based on fuel consumption of hybrid electric RCV.

The present work establishes a base that will allow future development of studies related to electric hybrid RCV's powertrain sizing optimization and control strategy.

\section{ACKNOWLEDGMENT}

The authors wish to acknowledge financial support from the Generalitat de Catalunya(GRC MCIA, Grant n SGR 2014101). The authors would also like to thank a partial financial support by the MINECO(Spain) under the Project CICYT TRA2013- 46757-R.

\section{REFERENCES}

[1] Nicholas Stern, "The Economics of climate Change: The Stern Review," Cambridge University Press, Jan. 2007.

[2] Maricarmen Crdenas Loera, "Calentamiento global y cambio climtico: El tratamiento del problema en los medios de comunicacin mexicanos (2008)," Tesis Doctoral, Universidad de Zaragoza, Espaa, 2010.

[3] Office of the Press Secretary, White house announces first ever oil savings standards for heavy duty trucks, buses [online]. The White House, Washington, DC, USA, 2011 Available: https://www.whitehouse.gov/thepress-office/2011/08/09/white-house-announces-firstever-oil-savingsstandards-heavy-duty-trucks

[4] F. Soriano, "A study of hybrid powertrains and predictive algorithms applied to energy management in refuse-collecting vehicles," Ph.D. dissertation, Polytechnic University of Catalonia, Barcelona, Spain, 2015.

[5] Aihua Wang and Weizi Yang, "Design of Energy Management Strategy in Hybrid Vehicles by Evolutionary Fuzzy System Part I: Fuzzy Logic Controller Development," Intelligent Control and Automation, 2006. WCICA 2006. The Sixth World Congress on, Dalian, 2006, pp. 83248328.

[6] Dembski, N., Rizzoni, G., Soliman, A., Fravert, J. et al., "Development of Refuse Vehicle Driving and Duty Cycles," SAE Technical Paper 200501-1165, 2005.

[7] T. Knoke and J. Bocker, "Optimal Power Train Design of a Hybrid Refuse Collector Vehicle," Vehicle Power and Propulsion Conference, 2007. VPPC 2007. IEEE, Arlington, TX, 2007, pp. 815-820.

[8] A. Ravey, N. Watrin, B. Blunier, D. Bouquain and A. Miraoui, "EnergySource-Sizing Methodology for Hybrid Fuel Cell Vehicles Based on Statistical Description of Driving Cycles," in IEEE Transactions on Vehicular Technology, vol. 60, no. 9, pp. 4164-4174, Nov. 2011.

[9] T. Nesch, T. Ott, S. Ebbesen and L. Guzzella, "Cost and fuel-optimal selection of HEV topologies using Particle Swarm Optimization and Dynamic Programming," American Control Conference (ACC), 2012, Montreal, QC, 2012, pp. 1302-1307.
[10] G. Souffran, L. Miegeville and P. Guerin, "Simulation of Real-World Vehicle Missions Using a Stochastic Markov Model for Optimal Powertrain Sizing," in IEEE Transactions on Vehicular Technology, vol. 61, no. 8, pp. 3454-3465, Oct. 2012.

[11] K. van Berkel, W. Klemm, T. Hofman, B. Vroemen and M. Steinbuch, "Optimal Control of a Mechanical Hybrid Powertrain With Cold-Start Conditions," in IEEE Transactions on Vehicular Technology, vol. 63, no. 4, pp. 1555-1566, May 2014.

[12] Zheng Chen, C. C. Mi, Jun Xu, Xianzhi Gong and Chenwen You, "Energy Management for a Power-Split Plug-in Hybrid Electric Vehicle Based on Dynamic Programming and Neural Networks," in IEEE Transactions on Vehicular Technology, vol. 63, no. 4, pp. 1567-1580, May 2014.

[13] X. Hu, N. Murgovski, L. M. Johannesson and B. Egardt, "Optimal Dimensioning and Power Management of a Fuel Cell/Battery Hybrid Bus via Convex Programming," in IEEE/ASME Transactions on Mechatronics, vol. 20, no. 1, pp. 457-468, Feb. 2015.

[14] D. Zhao, R. Stobart, G. Dong and E. Winward, "Real-Time Energy Management for Diesel Heavy Duty Hybrid Electric Vehicles," in IEEE Transactions on Control Systems Technology, vol. 23, no. 3, pp. 829-841, May 2015.

[15] Soriano, F., Alvarez-Florez, J., and Moreno-Eguilaz, M., "Experimentally Compared Fuel Consumption Modelling of Refuse Collecting Vehicles for Energy Optimization Purposes," SAE Int. J. Commer. Veh. 7(1):324-336, 2014.

[16] L. Guzzella and A. Amstutz, "CAE tools for quasi-static modeling and optimization of hybrid powertrains," in IEEE Transactions on Vehicular Technology, vol. 48, no. 6, pp. 1762-1769, Nov 1999.

[17] D. W. Gao, C. Mi and A. Emadi, "Modeling and Simulation of Electric and Hybrid Vehicles," in Proceedings of the IEEE, vol. 95, no. 4, pp. 729-745, April 2007.

[18] O. Sundstrom, P. Soltic and L. Guzzella, "A Transmission-Actuated Energy-Management Strategy," in IEEE Transactions on Vehicular Technology, vol. 59, no. 1, pp. 84-92, Jan. 2010.

[19] S. Ebbesen, P. Elbert and L. Guzzella, "Battery State-of-Health Perceptive Energy Management for Hybrid Electric Vehicles," in IEEE Transactions on Vehicular Technology, vol. 61, no. 7, pp. 2893-2900, Sept. 2012.

[20] L. Guzzella, A. Sciarretta. Vehicle Propulsion Systems, Introduction to modeling and optimization. Springer, 2013.

[21] Xi Zhang, Chris Mi. Vehicle Power Management, Modeling, Control and Optimization. Springer, 2011.

[22] A. Ostadi, M. Kazerani and S. K. Chen, "Hybrid Energy Storage System (HESS) in vehicular applications: A review on interfacing battery and ultra-capacitor units," Transportation Electrification Conference and Expo (ITEC), 2013 IEEE, Detroit, MI, 2013, pp. 1-7.

[23] M. Shahverdi, M. S. Mazzola, Q. Grice and M. Doude, "Pareto Front of Energy Storage Size and Series HEV Fuel Economy Using BandwidthBased Control Strategy," in IEEE Transactions on Transportation Electrification, vol. 2, no. 1, pp. 36-51, March 2016. 